\title{
O RETORNO AO PENSAMENTO DO SER NA FILOSOFIA DE HEIDEGGER
}

\author{
Ana Carla de Abreu Siqueira ${ }^{1}$ \\ Universidade Federal do Ceará (UFC) \\ https://orcid.org/0000-0002-3344-2863 \\ E-mail: carladeabreus@gmail.com
}

\section{RESUMO:}

O objetivo deste artigo é apresentar como o filósofo alemão Martin Heidegger propõe um retorno ao pensamento do ser. Em primeiro lugar, ele indica a importância de uma questão fundamental, a qual ficou esquecida pela tradição metafísica. Seu argumento revela que o pensamento do ser consiste na essência do pensar. Diante das ciências e da técnica, Heidegger defende a necessidade de resgatar pensamento do ser como uma tarefa primordial da existência humana e que nos possibilita fazer as perguntas em torno do sentido que os entes, o Ser em geral e nós mesmos possuímos.

PALAVRAS-CHAVE: Heidegger; Imagem do mundo; Metafísica; Pensamento; Ser.

\section{THE RETURN TO THE THOUGHT OF BEING IN HEIDEGGER'S PHILOSOPHY}

\begin{abstract}
:
This paper's purpose is to presente how the german philosopher Martin Heidegger proposes a return to the thought of being. At first, he points out the importante of this fundamental question, which was forgotten by the metaphysical tradition. His argument unfolds that thought of being is the essence of thinking. In times of sciences and technology, Heidegger defends the need to rescue this thought as a primordial task of human existence and that enables us to ask questions about the meaning that beings, Being in general and ourselves holds.
\end{abstract}

KEYWORDS: Heidegger; World Picture; Metaphysics; Thought; Being.

\footnotetext{
${ }^{1}$ Doutora em Filosofia pela Universidade Federal do Ceará (UFC), Fortaleza - CE, Brasil, onde foi bolsista Funcap. Este texto compõe parte da tese intitulada "Heidegger e a transformação do pensamento: pensar com a serenidade, a arte e a poesia", sob orientação do professor Dr. Fernando Barros.
}

SIQUEIRA, Ana Carla de Abreu. O retorno ao pensamento do ser na filosofia de Heidegger. Griot : Revista de Filosofia, Amargosa-BA, v.20, n.2, p.215-223, junho, 2020 . 
O filósofo alemão Martin Heidegger foi um crítico do sujeito pensante, porém, jamais negou que somos pensantes. Ele usa o constructo Dasein para indicar a dimensão concreta e temporal que pode fazer a pergunta pelo sentido do ser; não apenas do ser em geral, como também do seu próprio ser e dos entes que não possuem o seu mesmo modo de ser (HEIDEGGER, 2012, p.47). Com a analítica existencial do Dasein, seu propósito é destacar que existimos no mundo, estamos sempre ocupados e preocupados, desenvolvemos relações, somos criativos e seguimos em busca de bem estar. De forma semelhante, o pensamento também não está isento do mundo e de uma situação fática. Mas as ciências e a técnica seguiram um modo de pensar que se sustentava no domínio dos objetos por um sujeito que funda todo saber.

Apesar de trazer progresso e melhorar a vida em muitos aspectos, o conhecimento daí resultante seria depurado de uma meditação de sentido. Sem a pergunta pelo ser, também nos tornamos incapazes de questionar nossa própria existência, nossas possibilidades de ação ou qual o sentido de nossas escolhas, por exemplo. Após Ser e tempo (1927), Heidegger ainda procura mostrar que existe uma pergunta diferenciadora pelo sentido e que este discurso, o qual é em si anterior a qualquer experimento cientifico e imagem técnica, é capaz de nos fazer retornar à simplicidade que reside na tarefa de pensar. Embora tenha tecido a pergunta "o que significa pensar?", nosso autor já entendia que experimentar o pensamento é muito mais importante do que encontrar uma resposta definitiva para este tema que passou a ocupá-lo especialmente a partir dos anos 50 .

Em Washeisstdenken? (1952), tal pergunta possui quatro caminhos de reflexão possíveis e relacionados entre si: (1) saber o que é isso que chamamos de pensar; (2) investigar se a lógica consiste em sua forma tradicional; (3) descobrir se há requisitos necessários; (4) entender o que nos convida ao pensamento, sendo esta a questão mais decisiva ${ }^{2}$. Todas essas perguntas são feitas pelos seres humanos, uma vez que não existe outro ente pensante, como Heidegger defende ao dizer que:

O homem assume um papel especial no processo, no qual ele executa o pensamento. Todavia, o fato de que ele é o executor natural do pensamento não precisa de uma preocupação mais profunda na investigação do pensamento. Esse fato é por si compreensível. (HEIDEGGER, 2002b, 119)

É fundamental explicar que o verbo heißen quer dizer chamar tanto no sentido de "significar" como também preserva a noção de que se trata de um chamado, uma convocação. De forma evidente, isso passa despercebido com a tradução em língua portuguesa. $O$ filósofo busca aquilo que desvela nossa capacidade de pensar através da pergunta sobre o que nos leva a esse encontro e como ir a esse encontro, já que nem sempre estamos atentos ao pensar, pois se trata de algo que precisa de dedicação. Assim, ele afirma que "Para que sejamos capazes no pensar, temos que aprendê-lo. [...] $O$ pensar nós aprendemos na medida em que prestamos atenção ao que dá o que pensar." (HEIDEGGER, 2002b, pp.4-5). Somos invariavelmente capazes de pensar, mas diante dessa obviedade ainda não estamos tão aptos a dizer o que é isto que nos faz pensar. Devido a essas dificuldades, é compreensível o porquê de Heidegger ter afirmado, na famosa entrevista concedida para a Der Spiegel em 1966, que a conferência Washeisstdenken? era o seu texto menos lido (HEIDEGGER, 2009a, p.37).

Quando estamos presos aos problemas científicos ou à necessidade de produção técnica, deixamos de questionar qual o sentido dos nossos passos sobre a terra. A essência do pensamento

\footnotetext{
${ }^{2}$ No segundo e no terceiro sentidos da questão, são feitas avaliações sobre normas e proposições e, por isso, não caberá aqui seguir o processo sob tal perspectiva.
} 
só é desvelada quando o próprio ser se converte na direção de toda meditação (ZARADER, 1998, p.154). Segundo Heidegger, meditação é o pensamento do sentido e se mantém fora da busca constante por utilidade; também significa o modo reflexivo de todo Dasein em torno de si próprio, ao mesmo tempo em que se reconhece na convivência com o mundo e os outros. Ela é contraposta à representação, isto é, ao modelo pelo qual formamos nossas ideias a partir do que retemos de uma dada realidade. Para contextualizar as reflexões sobre o pensamento do ser contra a representação e sua emergência, é fundamental entendermos com qual período a teoria heideggeriana está em conflito.

No texto $A$ época da imagem do mundo (1940), o filósofo faz uma revisão da modernidade por meio de uma interpretação própria sobre os entes e o mundo. Ao contrário de ser em um mundo, dá-se na época moderna que o sujeito toma distância do mundo para gerar sua visão e inaugurá-lo como imagem. Isso não significa partir de uma visão de mundo, visto que esta se define como uma posição comum a quem é capaz de integrar ao seu comportamento e suas opiniões pessoais as visões trazidas pelos outros. A época da imagem do mundo é o período da imposição de um observador que quer conquistar o mundo enquanto uma imagem sua e, para isso, voluntariamente ocupa uma postura de superioridade nas suas tomadas de decisões. E tal postura se deu em um momento de crescente maquinação, ou seja, quando os homens recorriam a uma fabricação excessiva de produtos técnicos e úteis. Assim, as experiências vividas eram geradas pelo mesmo processo.

Essa época foi marcada por cinco fenômenos: a ciência, a técnica mecânica, a entrada da arte no horizonte da estética, a cultura e a desdivinização ou esquecimento dos deuses ${ }^{3}$. Diante de crescentes investigações e da busca por mais especialização, o sujeito se apodera dos entes para fazer experimentos e dominá-los de acordo com seus planos. Esse processo não se teria desenvolvido com os pensadores gregos originários, por exemplo, uma vez que eles se voltavam para as coisas mesmas sem interferir no modo como os fenômenos se mostravam em sua abertura. A época da imagem do mundo é aquela na qual o sujeito toma decisões sobre os entes e se mantém distante de qualquer passividade.

Em outros termos, o homem fundamenta e transforma o ente de acordo com suas concepções. Ao fazer o máximo de uso das suas capacidades, ele realiza projetos e define todo ente como objeto na medida em que o produz de forma prevista, organizada e ativa. É essencial lembrarmos que, quando fala em mundo, Heidegger está se referindo ao campo de acesso a todo sentido que reúne em si os entes, eventos e a natureza do qual somos inseparáveis. Sempre que o Dasein diz "eu sou", já deve estar subentendido que essa expressão significa "moro, detenho-me em... o mundo" (HEIDEGGER, 2012, p.173). Portanto, "imagem de mundo" é um termo amplo e revela muito mais do que uma cópia ou pintura de um quadro esboçado pelo sujeito. A expressão "imagem de mundo não quer dizer uma imagem do mundo, mas o mundo entendido como imagem." (HEIDEGGER, 2005, p.207) E ela se refere à época marcada pela representação do mundo e por cada projeção individual da sua totalidade.

Representar é trazer algo para diante de si e colocar-se na condição de referência incontestável, onde o sujeito alcança uma posição privilegiada e também faz parte da cena em que o ente aparece. Como consequência, é criada uma concepção de mundo segundo a qual o sujeito atribui uma importância aos entes dentro da vivência que pode ter com eles; e ele também se torna a própria medida da verdade, ainda que o mundo seja marcado por diversas concepções. As visões de mundo podem se tornar conflitantes, levando cada um a lutas constantes por domínio e "pela posição em que pode ser aquele ente que a todo ente dá a medida

\footnotetext{
${ }^{3}$ Cabe aqui destacar que a desdivinização é um evento que aproxima visão de mundo e experiência religiosa quando lhe dá um fundamento absoluto, semelhante àqueles que depositam possibilidades de existência no infinito. Além disso, toda experiência humana com os deuses estaria guiada somente pela religião, chegando a transformar toda visão do mundo em uma busca incessante pelos deuses e pela religiosidade. (HEIDEGGER, 2005, pp.191-2)
} 
e puxa o prumo." (HEIDEGGER, 2005, p.212). Por isso, diz-se que a época da imagem de mundo é o momento no qual não há desvelamento do ser, mas asseguramento dos entes.

O pensamento do ser se converteu no móbile da filosofia de Heidegger e recebeu novas narrativas a partir dos anos 30. Para investigar a essência do pensamento, é indispensável evitarmos os modelos de reflexão aos quais já estamos habituados. Afinal, cada um insiste em se dedicar mais às obras e atividades do que ao próprio exercício de pensar. A técnica e as ciências modernas testemunham que estamos usualmente voltados para os entes e deixamos a verdade do ser inexplorada. Ainda que o desvelamento do ser não constitua um problema relevante a todos, deveria ao menos ter uma discussão adequada na história da filosofia, uma vez que, nas palavras de Heidegger:

[...] a verdade do ser continua impensada. O esquecimento do ser se anuncia de modo mediato no fato de que o homem leva em consideração e trata sempre apenas do ente. $\mathrm{E}$ como ele não consegue contornar aí a representação do ser, mesmo o ser acaba sendo explicitado apenas como o 'ente mais geral', um ente que, por isto, abrange o ente; ou ainda como uma criação do ente infinito ou como o produto de um sujeito finito. (HEIDEGGER, 2008a, p.352)

O esquecimento do ser é uma questão basilar na estrutura de Ser e tempo, mas também atravessa todo o caminho filosófico heideggeriano. E essa questão antecede a busca pela essência do pensamento. Como defende Marlène Zarader na obra Heidegger e as palavras da origem, para falarmos de tal essência e aprendermos a pensar, antes é necessário colocarmos em discussão a questão do ser e sua primazia diante dos demais entes. A autora destaca no seguinte excerto:

\footnotetext{
Se o pensamento deve ser "dirigido para o ser", estar "à escuta do ser", trabalhar para "construir a casa do ser", não é simplesmente porque o ser é mais digno de ser pensado, ou mais susceptível de merecer uma questão, do que este ou aquele ente; mas é, em primeiro lugar e essencialmente, porque o ser é o país do pensamento, a sua pátria, o lugar onde ele nasce e cresce. (ZARADER, 1998, p.154)
}

Para isso, o filósofo percorre um trajeto que, em vez de inicialmente perguntar por alguma eficácia ou utilidade, realiza perguntas e tece reflexões que devem anteceder todas as investigações com as quais geralmente nos ocupamos. Heidegger adota como tarefa a “meditação que se demora no questionamento. As questões são caminhos para sua resposta. Estas questões deveriam, caso um dia realmente tomem forma, consistir numa transformação do pensamento" (HEIDEGGER, 2009b, p.65). Caso contrário, ficaríamos presos a representações. E ultrapassar este método representativo é superar as projeções estritamente pessoais que fazemos sobre os entes e o ser.

Por muito tempo, a filosofia se ocupou em saber se a representação está na mente ou na alma e, com isso, se há correspondência efetiva entre as coisas representadas e a realidade na qual estamos inseridos. Uma vez que o homem é ser-no-mundo, é impossível haver uma separação radical entre as coisas, o mundo e os homens. Essa teoria foi discutida em Washeisstdenken? com o exemplo de estarmos diante de uma árvore em flor. Para o ser-aí não recorrer a investigações científicas que transformariam a árvore em objeto, ele precisa abandonar uma noção de método dominador e deixar a árvore se revelar onde ela está situada, ou seja, dentro do mundo. Logo, a árvore não é uma imagem criada pela mente humana justamente porque a árvore e nós somos diante um do outro (HEIDEGGER, 2002b, p.44).

Fica evidente que o método representativo coloca objetos como criações da nossa mente e não deixa que as coisas sejam elas mesmas. Em outras palavras, é um pensar que não está comprometido com a verdade do ser, mas procura identificação entre uma imagem criada pela mente e a realidade externa, como neste conhecido caso da árvore já esboçado pelo 
fenomenólogo Edmund Husserl ${ }^{4}$. Heidegger sugere deixar a árvore em flor "onde ela está. [...] Porque o pensar até agora nunca a deixou estar ali, onde ela está." (HEIDEGGER, 2002b, p.46) O pensamento do ser se torna possível somente quando abandonamos as concepções exploratórias dos entes e realizamos um salto em direção a uma abertura para a manifestação do ser. Mas enquanto isso não acontece, o ser permanece o outro do ente e fica no esquecimento.

A questão do pensamento é a questão do ser, pois nela existe o projeto de pensar o ser. Para não correr o risco de transformá-lo em objeto ou produto, a análise de Heidegger evita a lógica formal da metafísica. É então que fica evidente o projeto de superação da metafísica, a qual buscava dar determinada estabilidade ao conceito de ser a partir do ente através dos olhos e da vontade do sujeito. Heidegger converte o ser em evento (Ereignis), onde homem e ser se pertencem na forma de um acontecimento apropriativo e mútuo. Nesse sentido, o ser jamais é interpretado como objeto determinado pelo sujeito, resultado de técnica ou simples presença. Homem e ser estão sempre em relação: o Dasein tem uma compreensão prévia e mediana do ser, o qual, por sua vez, se assemelha muito mais a uma iluminação projetada sobre a existência.

A seguinte afirmação de Gianni Vattimo revela o sentido genuíno do Ereignis: "quando o ser já não se pode pensar como simples presença, só pode aparecer como evento." (VATTIMO, 1998, p.116) E esse é o mais significativo e resplandecente de todos os eventos, visto que não há Dasein nem qualquer entidade sem o ser (HEIDEGGER, 2009c, p.28). Embora qualquer ente faça parte do mundo, apenas o homem é existência e, por isso, capaz de despertar para esse acontecimento. Nenhum outro ente pode viver a experiência de se espantar que as coisas sejam e se interessar pelo desvelamento do ser. Heidegger acredita que o pensamento faz parte do Dasein apenas porque o Dasein faz parte do ser. Em outras palavras, pensar significa colocar-se à escuta do ser e responder ao seu apelo. Isso se torna um acontecimento possível somente porque o ser não é determinado como uma obviedade, mas algo que se dá - apesar da tradição ter transmitido sua suposta evidência.

Heidegger demarca a ideia de que o ser desperta no pensamento. Só há pensar onde há possibilidade de revelação do ser: no Dasein, único ente capaz de fazer a pergunta de tudo que há e do seu próprio ser. Essa auscultação ao pensamento do ser consiste em um movimento interno a cada um de nós, porém, nunca se define como atitude estritamente subjetiva. Significa também um processo que leva a refletirmos sobre como nos damos conta do nosso ser-nomundo. Em Introdução à metafísica (1935), o filósofo critica qualquer teoria que (1) coloque o pensamento enquanto uma propriedade subjetiva diante do ser, onde este se mostra tomado como um objeto; e (2) segundo a qual o pensamento cria o ser e ambos se tornam criações subjetivas (HEIDEGGER, 1997, pp.150-1). Ele fala de uma implicação elíptica (ZARADER, 1998, p.142), pois responder a essa escuta é trazer o interesse pela questão do ser ao centro de indagações e entender que esse processo é comum apenas a quem se reconhece no ser.

Relatar a reciprocidade entre existência e ser levanta a questão sobre uma possível passividade do Dasein. No início de Carta sobre o humanismo (1946), Heidegger afirma que "O pensamento age na medida em que pensa." (HEIDEGGER, 2008a, p.326). Esse tipo de ação é diferente daquela que pretende provocar efeitos, trazer à revelação o uso de instrumentos e fazer experimentos. Trata-se de um agir intrínseco à própria facticidade, já que não se esgota quando alguma atividade é concluída. Ou melhor, é uma ação engajada com a verdade do ser, uma

\footnotetext{
${ }^{4}$ Husserl já havia tomado como exemplo de apuração dos vividos o "estar voltado para" uma árvore em flor: se eu olho para a árvore de acordo com a orientação natural, que é a postura comum às ciências positivistas (tais como as ciências exatas, a história e a psicologia, por exemplo), posso dizer que ela é real e que a percepção que me permite apreendê-la é um estado psíquico que necessariamente faz parte de mim; nesse caso, haveria a árvore efetiva e aquela criada por minha consciência. Por sua vez, na orientação fenomenológica, o que permanece depois da redução é a existência da relação entre o ato de perceber e o percebido. Em vez de ser criação da mente, um objeto solto ou resultado de uma alucinação, a macieira é a coisa mesma e a percepção da macieira é a vivência originária que me permite ter conhecimento dessa árvore. Se o seu tronco é derrubado, a coisa mesma é o objeto experimentado pela consciência após a suspensão dos juízos. (HUSSERL, 2006, pp.204-6)
} 
atitude que traz à presença a importância dos fenômenos e eventos. Deixar o ser simplesmente ser significa que o pensamento é uma ação ${ }^{5}$ engajada que só acontece na história, pois não se limita a exprimir a posição isolada que este ou aquele indivíduo possui.

Ao mesmo tempo, há o entendimento geral de que toda ação é precedida por um querer. Para Heidegger, o querer (Wollen) é uma elaboração impositiva através da qual o sujeito quer transformar tudo ao seu alcance em entes disponíveis e programados para sua própria realidade. Todo querer é uma elaboração e, por isso, ele age sob o pretexto de modificar o mundo e as relações humanas, como também suas principais decisões gravitam em torno de realizações técnicas (HEIDEGGER, 2002a, p.331-2). O problema nessa concepção é que o sujeito determina o que se deve constituir e apresentar como objeto, retornando ao esquema sujeito-objeto. No caso, até mesmo o ser dependeria de todo querer subjetivo, quando devemos reconhecê-lo por estar cercado de um caráter histórico.

Esse equívoco só acontece porque toda ação é geralmente vista como uma atividade técnica que tem como resultado algo novo. No contexto heideggeriano, agir significa trazer ao desvelamento e produzir algo previamente compreendido no seu modo de ser 6 . Enquanto um agir, pensar não precisa resultar em algo novo, do mesmo modo que o ser não consiste em alguma criação do pensamento ou de qualquer trabalho humano. Quando Heidegger evita afirmar que o ser é e passa a usar o termo presentar (Anwesenlassen), ele reforça a implicação mútua entre ser e tempo. Tais conceitos antecedem qualquer definição e, portanto, jamais são transformados em entes. Por outro lado, existe um aspecto do querer relevante no que diz respeito ao pensamento do ser.

Ainda em Carta sobre o humanismo, Heidegger afirma que é através "da capacidade do querer que alguma coisa pode propriamente ser." (HEIDEGGER, 2008a, p.329) Na proporção em que pensar é se colocar na escuta do ser, pensar significa uma tentativa de trazer o ser à presença de acordo com a estrutura da afetividade, pela qual nunca vivemos na indiferença nem sentimos desinteresse pelo ser. A afetividade ou disposição afetiva (Befindlichkeit) é o existencial que indica que o Dasein é afetado por eventos que se advêm sobre ele nos aspectos físico e afetivo, permitindo a qualquer um se encontrar em determinado estado de ânimo e de compreensão do mundo. O conceito também abriga em si aquilo que conhecemos como Stimmung, uma forma particular de sentir que se expressa por meio dos nossos humores cotidianos $^{7}$.

Pensar é uma postura humana que também está sustentada no espanto e na possibilidade de termos um vislumbre de que as coisas são além das imagens diante de nós. Heidegger justifica esse pertencimento do pensar à esfera da afetividade dizendo que:

Somente o homem, em meio a todos os entes, experimenta, chamado pela voz do ser, a maravilha de todas as maravilhas: o fato de que o ente é. Aquele que assim é chamado em sua essência para a verdade do ser está, por isto, continuamente afinado de uma maneira essencial. (HEIDEGGER, 2008b, p.319)

Essa passagem pressupõe que algo se mantém no velamento, atraindo a existência e chamando sua atenção pelo mistério que provoca. Daí resulta o reconhecimento de que há algo que nos perpassa, mas que, apesar disso, estamos desabituados a pensá-lo e então precisamos recordar. A memória é a faculdade que conserva fatos específicos na mente. Para Heidegger, sua tarefa vai além de reter o passado, pois ela consiste na guarda do ser que se movimenta nos três êxtases temporais que determinam o tempo enquanto "unidade de presente, passado, futuro"

\footnotetext{
5"Este “deixar' é a sua única acção; esta conformação com a injunção do ser é a sua única liberdade.” (ZARADER, 1998, p.156)

${ }^{6 “[\ldots]}$ a ação não poderia ser um começo absoluto, mas apenas continuação do que é, realização." (HAAR, 1997, p.135)

7 As reflexões sobre a afetividade se concentram, especificamente, nos $§ 29$ e 30 de Ser e tempo.
} 
(HEIDEGGER, 2009c, p.17) - e isso não expressa uma sucessão calculável de instantes. Quando falou nos êxtases temporais, o filósofo alemão quis dizer que ser é tempo, dado que nossa existência se faz nessa duração integrada entre passado, presente e futuro. É por essa razão que o tempo se constitui como horizonte de compreensão do ser.

Somos e só podemos viver em nosso próprio tempo, aceitando suas dádivas e lutando contra suas ameaças. Esse aspecto temporal permite a conservação do passado e a projeção em direção ao que está por vir. Mas se a memória for interpretada em seu sentido usual, ela se refere ao que ocorreu nas representações. Heidegger destaca que todo representar mostra apenas uma perspectiva, aquilo que é superficial nas coisas e, portanto, é insuficiente para indicar o caminho de pensamento que devemos seguir. E este é um caminho de rememoração, uma vez que, ao escapar de uma lógica formal e acumulativa, procura preservar o ser em todos os passos. A memória permite que o ser esteja presente mesmo quando parece estar ausente ou no esquecimento. Toda memória é incansável na tarefa de acolher aquilo que se pode desvelar e tudo o que pode vir a ser pensado não é somente imaginado nem criado exclusivamente pelo homem, senão também resgatado, rememorado.

Para entendermos qual relação está subentendida entre memória e pensamento, é essencial conhecermos a palavra denken e seus correlatos, os quais aparecem nas formas das palavras Gedanke (pensamento), Dank (agradecimento) e Gedächtnis (memória) (HAAR, 1997, p.140). De acordo com Heidegger, os termos possuem um significado muito mais profundo do que aquele que apresentam em seu uso habitual. $O$ verdadeiro agradecimento é guiado pela estrutura da afetividade: para agradecer, não recorremos apenas ao que está guardado na mente, mas também buscamos no coração aquilo que provoca nosso pensar. O agradecimento é "a coleta de tudo aquilo que nos diz respeito, tudo com que nos importamos, tudo que nos toca na medida como somos, enquanto seres humanos." (HEIDEGGER, 2002b, p.149)

É por isso que nunca somos meros animais racionais, pois já que recebemos a existência como um presente, somos capazes de reconhecer afetivamente essa dádiva e nos tornamos gratos simplesmente por existirmos. Sentimos gratidão por tudo que nos foi oferecido de algum modo. A própria capacidade de compreender o ser e perguntar por seu sentido é algo que jamais criamos. E o verdadeiro significado de agradecer é muito mais abrangente do que dar de volta algo que recebemos. No sentido pleno de reconhecimento, o agradecer permanece diretamente ligado à memória, pois reconhecer é o mesmo que retornar à própria origem e ao mistério da realidade. Logo, não é o homem que cria o que se pode pensar nem as invenções humanas constituem aquilo que mais propriamente nos convida a meditar.

Aquilo sobre o que a memória incide repousa na abertura ao ser e a abertura só é conquistada com o abandono de todo modelo investigativo que se preocupa com resoluções práticas para a vida cotidiana. Heidegger defende que o pensamento também é despertado pelo mistério, pela beleza e pelo agradável, nós apenas ainda não conseguimos resgatar essa cumplicidade (2002b, p.32). Dito em suas palavras, "Memória é a reunião do pensar sobre aquilo que em todas as partes deseja ser pensado antes de tudo. Memória é a reunião do rememorar." (HEIDEGGER, 2002b, p.13). Isso só é possível quando percebemos o quanto é grave o fato de ainda não estarmos pensando e então buscamos, a todo custo, apreciar essa disposição propriamente humana. Em meio a tudo isso, perguntamos: se o pensamento é memória, por que então acontece o esquecimento do ser? Porque ao invés de agradecer e retornar a tudo aquilo que provoca o pensamento, o ser-no-mundo se acostuma às coisas e situações que já estão desveladas ou então que ele mesmo cria através do trabalho cotidiano.

Apenas quando rememora é que ele se coloca à escuta de algo que não se faz presente de maneira óbvia, mas para o qual se pode retornar e reencontrar ao ter caído no esquecimento devido a tantas invenções. Marlène Zarader sustenta que "porque a sua tarefa é estar à escuta de seu próprio lugar que a própria natureza do pensamento - para além dos seus conteúdos - é 
definida por Heidegger como memória, lembrança ou pensamento fiel." (ZARADER, 1998, p.154). Portanto, a recordação provoca e mantém o pensamento em continuidade para além das ciências ônticas e dos saberes particulares, uma vez que é capaz de nos conduzir de volta à nossa origem, isto é, onde residem as perguntas fundamentais que nos movem.

Em todo esse processo de descobrir o que significa pensar - ou o que nos provoca o pensamento - o maior interesse de Heidegger é criar uma reflexão que conduza seus leitores e ouvintes a pensar. Assim, é notável como ele mesmo desenvolve o seu ofício de pensador, ante a observação de que:

O que 'significa' nadar, por exemplo, nunca aprendemos através de um tratado sobre natação. O que significa nadar, apenas o salto na correnteza nos diz. A pergunta "que significa pensar?' jamais se deixa responder através de um conceito sobre o pensamento, uma definição, e explicando seu conteúdo diligentemente. [...] Nós ficamos de fora da mera reflexão, que faz do pensamento seu objeto. (HEIDEGGER, 2002b, pp.22-3)

Com essa metáfora, Heidegger quis dizer que pensar é algo que só aprendemos pensando. $\mathrm{E}$ isso acontece apenas ao seguirmos um caminho de perguntas e reflexões em vez de estarmos presos a repetições de teorias já consolidadas em livros, o que facilmente converteria o pensamento em mero objeto de pesquisa. De certo, uma das maiores conquistas de Heidegger nesse mergulho foi encontrar no pensamento do ser a própria essência do pensamento. Portanto, a crítica à metafísica é essencial dentro da história da filosofia e seu propósito não é dizer que as questões filosóficas anteriores perderam validade. Por meio de um novo pensar, o objetivo do filósofo alemão é tirar o ser do esquecimento e colocar sua questão como a principal da filosofia. Ele salta da representação e das imagens em direção ao ser, com o propósito de superar a metafísica grega que deixou impensada a diferença entre ser e ente quando, assim destaca Mafalda Blanc, coloca o ser enquanto presença incessante ao invés de um horizonte a partir qual nós podemos entender os entes.

Heidegger quis superar a metafísica moderna que estava sustentada no a priori do sujeito e no saber científico que investiga, caracteriza e objetifica os entes (BLANC, 2014, pp.111-2). Com efeito, a questão do ser escapa de todo domínio técnico, de métodos empíricos e da busca por uma utilidade imediata. Em uma tradição marcada pelas ciências, pela técnica e pela presença inconsiderada da tecnologia, perguntar pelo sentido do ser requer outro pensar. Isso não se trata de algo novo e criado pelas mãos humanas, senão de algo simples e essencial, uma marca indelével de que somos pensantes e, ao mesmo tempo, afetivamente ligados ao mundo e aos outros. Somente retornando ao pensamento do ser é que conseguimos romper com qualquer alienação de que seríamos fundadores de toda verdade. E somente reconhecendo que somos incapazes de definir o ser, é que seguimos as correntezas do pensamento. 


\section{Referências}

BLANC, Mafalda. "O problema da metafísica em Heidegger no período de gestação de Ser $e$ tempo", in: Philosophica, Lisboa, n.43, pp. 99-114, 2014.

HAAR, Michel. Heidegger e a essência do homem. Trad. Ana Cristina Alves. Lisboa: Instituto Piaget, 1997.

HEIDEGGER, Martin. "A época da imagem do mundo", in: SCHNEIDER, Paulo Rudi. $O$ outro pensar. Trad. Paulo Rudi Schneider. Ijuí: Unijuí, 2005.

HEIDEGGER, Martin. "Carta sobre o Humanismo", in: Marcas do caminho. Trad. Enio Paulo Giachini e Ernildo Stein. Petrópolis: Vozes, 2008a.

HEIDEGGER, Martin. Introdução à metafísica. Trad. Mario Matos e Bernhard Sylla. Lisboa: Instituto Piaget, 1997.

HEIDEGGER, Martin. "Já só um deus nos pode ainda salvar", in: Der Spiegel. Trad. Irene Borges-Duarte. Covilhã: Luso Sofia: press, 2009a. Entrevista concedida a revista alemã Der

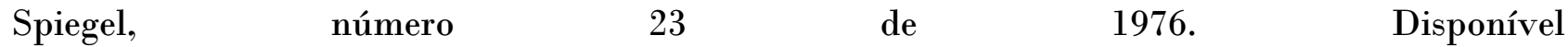
em:http://www.lusosofia.net/textos/heideggger_ja_so_um_deus_nos_pode_ainda_salvar_der_spi egel.pdf. Acesso em: 15 de abril de 2019.

HEIDEGGER, Martin. "O fim da filosofia e a tarefa do pensamento", in: Sobre a questão do pensamento. Trad. Ernildo Stein. Petrópolis: Vozes, 2009b.

HEIDEGGER, Martin. "Para quê poetas?", in: Caminhos de floresta. Trad. Bernhard Sylla e Vitor Moura. Lisboa: Edição da Fundação Calouste Gulbenkian, 2002a.

HEIDEGGER, Martin. "Posfácio a 'O que é metafísica?"”, in: Marcas do caminho. Trad. Enio Paulo Giachini e Ernildo Stein. Petrópolis: Vozes, 2008b.

HEIDEGGER, Martin. Ser e tempo. Trad. Fausto Castilho. Campinas: Editora Unicamp; Petrópolis: Vozes, 2012.

HEIDEGGER, Martin. "Tempo e ser", in: Sobre a questão do pensamento. Trad. Ernildo Stein. Petrópolis: Vozes, 2009c.

HEIDEGGER, Martin. Washeisstdenken? Vittorio Klostermann. Frankfurt am Main, 2002b.

HUSSERL, Edmund. Ideias para uma fenomenologia pura e para uma filosofia fenomenológica. Trad. Márcio Suzuki. Aparecida: Ideias \& Letras, 2006.

VATTIMO, Gianni. Introdução a Heidegger. Trad. João Gama. 10a edição. Lisboa: Instituto Piaget, 1998.

ZARADER, Marlène. Heidegger e as palavras da origem. Trad. João Duarte. Lisboa: Instituto Piaget, 1998.

Autor(a) para correspondência: Ana Carla de Abreu Siqueira, Av. Universidade, 2995, Benfica, CEP 60020-181, Fortaleza-CE, Brasil. carladeabreus@gmail.com 